\title{
PARA SILENCIAR OS CAMPI
}

\author{
ROBERTO LEHER
}

\begin{abstract}
RESUMO: $\mathrm{O}$ artigo examina se as medidas encaminhadas pelo governo de Lula da Silva, como o Programa Universidade para Todos (PROUNI), o Sistema Nacional de Educação e o Projeto de Lei de Inovação Tecnológica, configuram uma ação articulada sobre a educação superior e, em caso afirmativo, se é possível apreender um eixo que torne inteligível o curso dessas açoes. O trabalho sustenta que é a Parceria Público-Privado que conecta estas iniciativas e que, por isso, é possível captar um sentido para as mudanças esperadas na universidade pública brasileira. A investigação analisa os pressupostos e as consequiências prováveis do Projeto de Parceria Público-Privado, discute as suas expressões na educação superior - o PROUNI e a Inovação -, concluindo que estas movimentações estabelecem que o veio axial da expansão da educação superior se dará por meio do fornecimento privado subsidiado por verbas públicas, opção que reduz o número de novas matrículas. As parcerias público-privado (Inovação e PROUNI) redefinem as instituições públicas, contribuindo para o apagamento da fronteira moderna entre o público e o privado, convertendo a educação em mercadoria e a universidade em lugar de capitalismo acadêmico. Com a erosão do conceito de "espaço público de produção do conhecimento", a crítica sofrerá severa restrição, sobressaindo o problema da liberdade acadêmica.
\end{abstract}

Palavras-chave: Universidade. Política educacional. Inovação tecnológica. Público. Privado. Produção de conhecimento.

\section{TO SILENCE THE CAMPI}

ABSTRACT: This paper wonders if the measures taken by the Lula Da Silva administration, such as the Universidade para Todos Project (prouni), Sistema Nacional de Educação and Projeto de Lei de Inovação

Doutor em Educação pela Faculdade de Educação da Universidade de São Paulo (FEUSP) e professor da Faculdade de Educação da Universidade Federal do Rio de Janeiro (UFRJ). E-mail: rleher@uol.com.br 
Tecnológica, configure an articulated action about higher education and, if they do, whether one can apprehend a thrust that turns their course intelligible. It advocates that it is the Public-Private Partnership that connects these initiatives, and thus allows us to encounter a meaning for the expected changes in the Brazilian public universities. The text then analyzes the conjectures and probable consequences of the Public-Private Partnership Project, and discusses their expressions in higher education - PROUNI and Inovação - to conclude that these movements show that the main thrust of the higher education expansion will be a private supply subsidized by public resources, an option that reduces the number of new enrollments. The Public-Private Partnership (Inovação and PROUNI) redefines public institutions and contributes to erasing the modern border between public and private, converting education into a commodity and universities into a place of academic capitalism. With the erosion of the concept of public space as a place of knowledge production, criticism will suffer severe restrictions, which will bring the problem of academic freedom again.

Key words: University. Educational policies. Technological innovation. Public. Private. Knowledge production.

final, existe uma política para a educação superior brasileira sendo encaminhada pelo governo de Lula da Silva? A julgar pelo posicionamento recente do Ministério da Educação (2004), até o presente momento o governo tão-somente apresentou "princípios e diretrizes" para a reforma, estando o processo aberto ao debate democrático com as entidades representativas. A realização de plenárias nacionais para impedir o avanço da "reforma" e o posicionamento do Fórum Nacional em Defesa da Escola Pública (FNDEP), criticando pontos nodais das medidas governamentais para a educação superior, como o Programa Universidade para Todos, e sustentando que a educação não é mercadoria, sugerem que uma "reforma" está em curso. Como, obviamente, não se trata apenas de identificar quem tem razão, mas, antes e principalmente, de tentar captar o movimento do real, é preciso sair do plano discursivo já dado e mesmo do exame da "letra da lei" como "dados da realidade" e lograr apreender em pensamento os seus determinantes fundamentais. Entender as grandes linhas dos fenômenos que "leis e discursos oficiais" podem estar determinando é, também, indagar: se existe uma reforma, qual o seu objetivo? 
Francisco de Oliveira, em oficina de trabalho do Observatório Social da América Latina do Conselho Latino-Americano de Ciências Sociais (CLACSO), realizada no Laboratório de Políticas Públicas da UFRJ, nos dias 8 e 9 de agosto de 2002, argumentava que os conflitos sociais estão cada vez mais opacos. Weberianamente, seria possível sustentar uma espécie de reencantamento do mundo e, nos termos clássicos de Marx, uma fetichização tão fantástica que a possibilidade de distinguir entre a aparência e a essência, entre a forma e o conteúdo, tornou-se muito mais difícil. A prioridade conferida a determinados aparelhos de hegemonia pelos "senhores do mundo", como as escolas e as universidades, por exemplo, tornou as ideologias que neles circulam mais penetrantes, provocando disposições de pensamento ainda mais profundas. É preciso, portanto, uma consistente operação teórica para sair do mundo das manifestações fenomênicas e da representação imediata do real. Somente com apoio da teoria e da crítica aos conceitos que se restringem a descrever o concreto é que será possível chegar à rica totalidade que, de fato, explique o real em seu movimento.

Por isso, ainda que necessário, não basta elencar, classificar, hierarquizar e catalogar projetos de lei, medidas provisórias, decretos e portarias. É preciso apreender as suas conexões com as grandes orientações das políticas governamentais. Caso contrário, o ministro da Educação, Tarso Genro, teria razão de argumentar que o simples fato de o governo estar criando leis e normas nega, a priori, a possibilidade de que as políticas do MEC sejam neoliberais. Entretanto, a existência de ações do Estado não é contraditória com a crença no livre mercado, o núcleo sólido do pensamento neoliberal. O magistral trabalho de Polanyi (2000), A grande transformação, demonstra, de modo brilhante, como o mercado resultou de uma construção social deliberada a partir do Estado e, portanto, de suas leis e normas. Como a organização e a classificação das medidas governamentais não fornecem os elementos heurísticos para entender o movimento do real, cabe ao pesquisador enfrentar o problema dos conceitos e das categorias que permitem tornar pensável o real. O presente estudo propugna que a comodificação da educação vem sendo operada também por intermédio do Estado.

Sem teoria e indagações, o pesquisador pode se contentar em examinar as medidas encaminhadas no âmbito do Ministério da Educação, ignorando ou, pelo menos, secundarizando as disposições elaboradas na área econômica. Tampouco bastaria selecionar as ações econô- 
micas afins à área educacional, é preciso ir mais além, fazer um esforço analítico sistemático para captar a dinâmica interna do concreto. Marx, mais do que qualquer outro pensador, demonstrou que é característica do capitalismo a densa opacidade dos fenômenos e processos sociais. É essa opacidade que torna a análise cada vez mais importante, embora cada vez mais difícil.

Aparência e essência conformam uma dialética. Marx argumentava que os processos sociais se reproduzem na aparência, mas, como se sabe, a mais-valia não se revela no mundo das aparências. Somente pela crítica a Ricardo e Smith foi possível desvendar o segredo da mercadoria. Igualmente, é preciso investigar as formas - leis, decretos etc. - mas sem esquecer que as formas estão completamente imbricadas com as suas determinações mais profundas como as relações de classes, o lugar da educação na agenda da fração dominante e o grau de organização da classe que vive do próprio trabalho. Um dos pressupostos mais reiterados pelo discurso dominante sobre a educação é a afirmação de que esta, se congruente com a revolução científico-tecnológica, permite inserir as naçóes da periferia e da semiperiferia no admirável mundo globalizado e de que todos os que fizerem opções educacionais corretas terão um futuro grandioso. Essa forma da "verdade" é exaustivamente repetida pelos meios de comunicação. Mas, de fato, é a educação a nova riqueza das nações ou essa proposição faz parte de um processo de mercantilização e de ideologização da educação?

Essa profunda imbricação entre forma e conteúdo e entre a aparência e a essência compõe a nervura do real a que se refere Marilena Chaui (1999). Mas a ideologia neoliberal é tão exitosa (Anderson, 2003) que as disposições de pensamento (Thernborn, 1987) provocadas por ela produzem, pelo excesso de luz, a cegueira a que se refere o aterrador romance de Saramago Ensaio sobre a cegueira. Francisco de Oliveira, na conferência citada, valeu-se da belíssima imagem evocada por Theo Angelopoulos em seu magnífico filme "Paisagem na Neblina" (1988), na qual a neblina é tão espessa que nem faróis de mercúrio permitem ver o caminho. O único modo de caminhar na densa opacidade sem correr riscos ou se perder na bruma é por meio da teoria.

Essa opacidade vai sugerir revisões, reestruturação e talvez a invenção de novos procedimentos metodológicos para poder trabalhar com os "dados". O governo de Lula da Silva, por estar envolto por uma aura de esquerda, pode dar nova forma à agenda neoliberal, tornando-a mais opa- 
ca e difícil de ser analisada e combatida. Essa questão é crucial para o debate sobre as medidas que afetam a educação superior. É muito fácil se perder no mundo das manifestações fenomênicas em uma situação em que a fetichização das formas é mais eficaz. Quando o Executivo apresenta o Programa Universidade para Todos (PROUNI) ${ }^{1}$ para a sociedade, o que é mostrado é sobretudo a imagem de que, doravante, os muito pobres, os negros e os egressos das escolas públicas finalmente terão acesso à educação superior. Somente com esforço teórico e analítico, é possível concluir que a sua essência é o estabelecimento de Parcerias Público-Privado também no campo da educação. Mas isso não é visível imediatamente: o excesso de luz (Saramago) e a opacidade da neblina (Angelopoulos) afastam essa dimensão da esfera do imediatamente visível.

$\mathrm{O}$ presente ensaio argumenta que, para tornar inteligíveis as diversas medidas em curso - SINAES, GTI, PROUNI, PL de Inovação Tecnológica, Regulamentação das Fundações Privadas, Documento II etc. ${ }^{2}-$, é preciso examinar o que é a determinação mais crucial desses projetos e encaminhamentos. Qual a sua nervura axial? A hipótese de trabalho aqui sustentada propugna que as Parcerias Público-Privado (Brasil, 2003a) são o fio de Ariadne que conduz à determinação mais profunda dessas medidas: a redefinição radical da relação público-privado na educação, equiparando todas as instituições que atingirem um patamar mínimo de desempenho no SINAES, como "instituiçôes de interesse social". Como pode ser visto adiante, a indiferenciação entre o público e o privado é o ponto nodal do Acordo Geral de Comércio de Serviços da OMC. E nesse ambiente reconfigurado, não há espaço para a liberdade acadêmica. Não se trata, por conseguinte, de um problema estritamente econômico. As implicações políticas são severas.

\section{PPP, novas modalidades de privatização e o fim da fronteira entre o público e o privado}

A crença de que o mercado é mais capaz de prover as necessidades individuais e sociais que o Estado é um dogma do governo de Lula da Silva. O Projeto de Lei que dispõe sobre as PPP (PL n. 2.546/2003) é apresentado socialmente como um divisor de águas: após sua aprovação, novos empreendimentos terão lugar em praticamente todos os setores da economia. Liderado pelo setor privado, o crescimento econômico conhecerá índices que colocarão o país entre as nações mais ricas e poderosas 
do planeta. Como forma, a Ppp é apresentada como uma genial idéia: em troca de algumas garantias, o setor privado irá aportar um grande volume de recursos nos setores de infra-estrutura, educação, ciência e tecnologia etc.

Essa mesma avaliação é compartilhada pelo Banco Mundial, pelo Banco Interamericano de Desenvolvimento e pelo FMI. O interesse desses organismos na matéria é forte. $\mathrm{O}$ governo brasileiro acertou com a chefe da Missão do FMI, Teresa Ter-Minassian, que o Projeto das PPPs, ${ }^{3}$ o PL de Inovação Tecnológica e o de Lei de Falências devem ser as prioridades da pauta do Parlamento nacional. Instigante artigo de Ceci Juruá (2004), publicado no sítio Outro Brasil (www.outrobrasil.net), coloca a questão sob um outro prisma. A autora indaga se o PPP não seria a terceira etapa do processo de recolonização do Brasil, após as privatizações e a Lei de Responsabilidade Fiscal, que promoveram o desmonte do Estado desenvolvimentista.

Os pressupostos de que o Estado não dispóe de riqueza para promover novos investimentos e de que é notório que o setor privado é mais eficiente no uso de recursos justificam a opção por contratos do Estado com o setor privado para fornecer todas as atividades outrora empreendidas pelo Estado. Cumpre observar que, pelo PL, toda ordem de "serviços" poderia ser objeto desse tipo de parceria, conforme manifesto em seu art. 1\%, parágrafo único:

Esta Lei se aplica aos órgãos da administração direta, aos fundos especiais, às autarquias, às fundaçôes públicas, às empresas públicas, às sociedades de economia mista e às demais entidades controladas direta ou indiretamente pela União, Estados, Distrito Federal e Municípios.

O alcance dessas parcerias é ainda mais amplo que o previsto no Plano Diretor da Reforma do Estado, de Cardoso: "Art. 3o) Pode ser objeto de parceria público-privada: I - a delegação, total ou parcial, da prestação ou exploração de serviço público, precedida ou não da execução de obra pública”.

Desse modo, excetuando o poder de regular, legislar e policiar, todo o restante pode ser objeto de PPP. Assim, a educação, a pesquisa C\&T, o meio ambiente e a saúde, por exemplo, poderão ser objeto dessas parcerias. Dessa forma, caberão ao setor privado as decisões sobre investimentos governamentais: as resoluções de investimentos ficarão por conta dos investidores privados que os selecionarão de acordo com os seus cri- 
térios de poder de mercado e de maximização de lucros. Evidentemente, nesse escopo não cabem políticas públicas universalizantes. A focalização de nichos de mercado provavelmente será a regra. Se houver financiamento público, setores mais pobres podem ser alcançados com políticas assistenciais, nos termos das políticas de "aliviamento à pobreza" do Banco Mundial; se houver possibilidade de explorar tarifas e taxas, certamente os setores mais favorecidos serão alcançados por essas parcerias.

Essa modalidade de contrato foi originalmente encaminhada na Inglaterra, depois que os efeitos negativos das privatizações de Thatcher ficaram evidenciados: o capital não se mostrou disposto a investir em infra-estrutura de longo prazo, a não ser em troca de altas tarifas que afetariam os custos de outras fraçóes do capital. O sucessor da Dama de Ferro, o primeiro-ministro John Major, reconheceu que, em diversos segmentos, o setor privado não faria investimentos e, por isso, o Estado teria de subsidiá-los. Com base nesse mecanismo de repasse de recursos públicos para o setor privado, uma nova onda de privatizaçōes foi possível - em especial em domínios nos quais o capital não mostrou disposição de investir. É esse modelo que está sendo encaminhado no Brasil (Caliari, 2004). Por isso, conforme o Instituto de Estudos Socioeconômicos (INESC), "na verdade o PPP é uma forma de privatização de setores e serviços públicos estratégicos. Criaram um novo nome para uma coisa antiga e conhecida de todos" (Nunes, 2004).

No caso do governo brasileiro, a convicção de que a esfera privada é superior à esfera pública, em todos os sentidos, não é tão recente. Desde meados dos anos de 1990, por exemplo, a Articulação Sindical, a corrente majoritária na CUT e no PT, vem direcionando sua agenda política para acordos e pactos com empresários, excluindo de suas estratégias o Estado Social. O caso da formação profissional é emblemático. Em vez de apostarem nos centros públicos, optaram por utilizar as verbas do Fundo de Amparo ao Trabalhador em organismos privados. A admissão de que as principais políticas sociais - e de infra-estrutura - podem ser protagonizadas pelo empresariado por meio de Parcerias Público-Privado (PPPs) vem sendo operada desde as mudanças constitucionais (Reforma do Estado) realizadas por Cardoso. Quanto à crença de que o setor privado é sempre mais eficiente que o público, tanto como lembrar as fraudes da Enron e da Parmalat, é preciso recordar que, a despeito das verbas públicas repassadas às instituições privadas de educação, a qualidade dessas instituiçóes, com as exceçôes de praxe, é sabidamente insuficiente. 
O outro pressuposto, de que o Estado não dispõe de recursos para novos investimentos, igualmente não se sustenta. ${ }^{4}$ A coalizão de classe dos últimos governos é liderada pelo capital rentista e isso pesa nas contas públicas. $\mathrm{O}$ governo remunera os títulos de sua dívida com uma taxa real de juros que se situa entre as maiores do mundo. Como lembra Juruá (2004), a dívida mobiliária federal interna passou de $\mathrm{R} \$ 650$ para $\mathrm{R} \$$ 737 bilhões no curto espaço de dez meses, entre março de 2003 e janeiro de $2004 .{ }^{5} \mathrm{O}$ acréscimo de $\mathrm{R} \$ 87$ bilhões na dívida pública significa um aumento superior a $\mathrm{R} \$ 13$ bilhōes no fluxo anual de juros, quantia mais do que suficiente para uma profunda transformação da educação pública em todos os níveis e modalidades.

É preciso destacar as aparentemente despretensiosas salvaguardas que estariam sendo oferecidas ao setor privado para encorajá-lo a promover investimentos não tão secundários assim. A predatória burguesia autóctone não aceita correr riscos e, por isso, essas parcerias terão de contar com toda a sorte de proteção por parte do fundo público. Daí é que, desconfiados da capacidade operativa do atual governo, os empresários da Câmara Americana do Comércio estão tentando "blindar" as PPPs contra riscos políticos e econômicos, exigindo garantias fiscais e regulatórias, pleito que conta com o apoio da área econômica.

Com efeito, conforme Nota Técnica do INESC (Nunes, 2004), o Estado nacional assumirá grande parte dos riscos dos investimentos, permitindo e garantindo o aumento de tarifas, a emissão de títulos do Tesouro e a entrega do patrimônio público com garantia para os investimentos do setor privado. A despeito dos ares de modernidade, prevalece o velho patrimonialismo. A Lei de Licitações, por exemplo, deixará de ser aplicada em vários aspectos. Assim, mecanismos de corrupção poderão ser reforçados: a justificativa para a escolha de um determinado "parceiro" dependerá de comissão indicada pelo próprio governo, sem nenhuma forma de controle social. O Estado poderá se endividar sem qualquer controle social e do Parlamento, abrindo novos caminhos para o uso particularista do poder de Estado. No caso dos contratos internacionais, e a regra será essa principalmente caso venha a prevalecer o ALCA (notadamente nas áreas de investimentos e compras governamentais), a arbitragem sobre os contratos nem terá a participação do Poder Judiciário nacional, visto que prevalecerá a arbitragem internacional. Um outro ponto a destacar, ainda conforme o INESC, é que, nos termos do Plano Plurianual, os recursos privados não ultrapassarão meros $15 \%$ até 2007 , 
corroborando a suposição de que as verbas públicas serão a base dessas parcerias. E a educação não escapa dessa lógica, conforme pode ser visto adiante. Os contratos possuem condições extremamente vantajosas para o capital, podendo vigir até por 30 anos (art. 4º, I), e, ademais, o Estado oferece toda sorte de garantias para o provedor privado que, rigorosamente, faz um capitalismo sem riscos (arts. 6o a $9^{\circ}$ ).

Não deveriam surpreender, portanto, que os primeiros atos encaminhados pelo governo de Lula da Silva para "reformar" a universidade pública brasileira objetivem jogar abaixo as fronteiras edificadas, na Modernidade, entre o público e o privado (Dupas, 2003), em que todas as instituições, independentemente de sua natureza jurídica, farão parte da "cruzada do presidente Lula" para ampliar o acesso ao ensino superior.

Essa proposição é congruente com o documento do Ministério da Fazenda (2003) sobre os gastos sociais, em que Joaquim Levy e Marcos Lisboa, dois destacados dirigentes, em fina sintonia com o Consenso de Washington II, identificam na gratuidade do ensino superior público a origem das injustiças nos gastos sociais, sugerindo, como alternativa, parcerias do Estado com o setor privado. As mesmas posiçōes podem ser encontradas em relatório de uma comissão interministerial (GTI ${ }^{6}$ que assevera que os estabelecimentos julgados pelo sistema de avaliação como "eficientes" farão jus às verbas públicas, independente de serem públicos ou particulares.

Além do Ppp, um projeto "guarda-chuva", existem medidas que incidem diretamente sobre a universidade: o Programa Universidade para Todos (PROUNI) (observe-se a ausência do adjetivo pública) e o PL de Inovação Tecnológica. No primeiro projeto, por meio de gigantesca renúncia fiscal, que poderá ultrapassar $\mathrm{R} \$ 2,0$ bilhões/ano, montante equivalente a mais de $1 / 3$ do orçamento de todas as instituições federais de ensino superior, o Estado irá comprar vagas do setor privado, metamorfoseando-as em vagas "públicas" (porém não gratuitas), como é possível constatar na MP 213 que instituiu o PROUNI. A outra face dessa diluição da fronteira entre o público e o privado é o Projeto de Lei de Inovação Tecnológica, originalmente de autoria de Cardoso e redimensionado pelo atual governo. As universidades serão inseridas no moinho satânico da reprodução do capital, colocando à disposição laboratórios, equipamentos e, principalmente, pessoal para iniciativas empresariais, como se as 
empresas locais estivessem demandando a produção de tecnologias e, ainda mais inverossímil, como se as inovações tecnológicas nascessem nas universidades. Em troca, as instituições receberiam alguma compensação econômica por parte das empresas, desde que abram mão de seu caráter público e não-mercantil. Em suma, é a institucionalização do "capitalismo acadêmico".

A ida de Tarso Genro para o Ministério da Educação coloca em relevo a importância do Projeto de Lei n. 2.546/2003 que dispõe sobre as PpPs. Na Exposição de Motivos (Brasil, 2003c) do referido PL, é mencionado o empenho da Secretaria Especial do Conselho de Desenvolvimento Econômico e Social (SEDEs), então dirigida por Genro, em sua viabilização. As declarações de que o MEC pretende estabelecer parcerias para obter vagas "públicas" nas instituiçôes privadas apenas corroboram a afinidade com o projeto em exame. Matéria de $O$ Estado de S. Paulo (Hashizume, 2004) relata:

Uma parceria público-privada (PPP) para disponibilizar vagas públicas em universidades privadas. Assim pode ser definida a parte aparente do Programa Universidade Para Todos, apresentado nesta segunda-feira (16/2/04) pelo Ministério da Educação (MEC). Como prêmio por essa "doação" de cadeiras para alunos ao Estado, as instituições do setor privado ficarão isentas de impostos e contribuições federais.

O estabelecimento desse tipo de parceria na educação terá implicações profundas, repercutindo em todos os níveis e modalidades. Essas parcerias redefinem o dever do Estado na realização do direito à educação, ampliando a esfera privada em detrimento da esfera pública. $\mathrm{O}$ superávit primário acordado com o FMI não prevê recursos adicionais para a educação superior pública, conforme o Plano Plurianual que se encerra em 2007. A indistinção entre as instituições públicas e privadas contraria diversos aspectos da Constituição Federal, mas atende a um objetivo há muito reivindicado pelos empresários da educação, nacionais e estrangeiros (Aboites, 2001).

Tanto o ministro Tarso Genro como o secretário executivo do MEC sustentam a necessidade de suprimir a idéia de que existem diferenças entre a educação pública e a educação privada, visto que ambas atendem ao "interesse público". Nos termos do secretário executivo:

Nós pretendemos quebrar um muro que separa hoje as instituições privadas das públicas, aproximar os dois sistemas com benefícios mútuos. 
(...) Ou seja, estamos pensando agora o setor em termos sistêmicos, e não mais de forma compartimentada, sem coesão e sem coerência interna. (Hashizume, 2004; grifos meus)

\section{A mesma perspectiva é defendida pelo Ministro:}

O papel que as universidades privadas vão ocupar no ensino superior brasileiro vai ser definido por essa relação que nós estamos estabelecendo com eles e pelo conteúdo da reforma da universidade. Por isso que as duas coisas são inseparáveis. Essa reforma não é somente da estrutura pública, é uma reforma da relação público-privada a partir do critério do interesse público. E esse movimento é um movimento inicial (...). (Idem, ibid.; grifos meus)

O estabelecimento privado que tem fins mercantis e a universidade pública e gratuita passam a ser um único sistema e, naturalmente, ambos deverão possuir o mesmo direito de receber os recursos do Estado, desde que atendam aos requisitos do sistema de avaliação e que tenham "compromisso social". O "Pacto da educação para o desenvolvimento inclusivo" (Relatório do GTI), ao prever editais para aquisição de vagas indistintamente para as universidades públicas e privadas, operacionaliza esse propósito. Mais amplamente, a encomenda de vagas "públicas" nas instituições privadas, já efetivada pela MP 213, é um passo incomensurável no apagamento da fronteira entre o público e o privado. Com as PPPs, existirá um único sistema indiferenciado e, "dada a maior eficiência do setor privado", conforme reconhece a Exposição de Motivos do mencionado PL, logo o fornecimento "público", por meio das privadas, alcançará uma proporção tal que tornará as matrículas das universidades públicas minoritárias também dentro do que seria, outrora, a esfera pública, agora redimensionada como pública não-estatal. $\mathrm{O}$ secretário Haddad é direto quanto ao lugar secundário das públicas: "Da mesma forma que, se houver espaço orçamentário, nós temos que ampliar as vagas das universidades públicas" (idem, ibid.; grifos meus).

\section{PROUNI: PPP na educação superior}

O PROUNI vem ao encontro dos mais ambiciosos sonhos das instituições filantrópicas, comunitárias, confessionais e empresariais de educação superior. Após décadas de isençōes fiscais e da contribuição patronal para a Previdência Social (superior a $20 \%$ do custo da folha de pagamentos), benefícios que correspondem a um subsídio público de 
$25 \%$ em seus gastos totais, aporte que equivale à cerca de $\mathrm{R} \$ 840 \mathrm{mi}$ lhôes ao ano, as instituições filantrópicas, que reúnem grande parte das maiores instituições de ensino superior do país, poderão fazer associações com empresas estrangeiras - a exemplo do que ocorre hoje entre o Pitágoras do ministro Walfrido Mares Guia e a Apollo International (Rosenburg, 2002) -, vender patrimônio adquirido com isençôes fiscais, como aviōes, prédios, terrenos etc., remunerar os seus sócios, distribuir lucros e deixar o patrimônio como herança, tudo isso sem deixar de continuar a receber magnânimo apoio do Estado: mesmo na condição de instituições empresariais, gozarão de completa isenção de impostos, o que reduz em cerca de $15 \%$ os seus gastos em troca de modestíssimas vagas.

Somente após cinco anos os empresários, agora não apenas de fato, mas também de direito, estarão pagando a integralidade da contribuição patronal para a Previdência Social. A opção por favorecer os que vêm se beneficiando do estatuto da filantropia não pára nessas isenções e na referida possibilidade de transformação da natureza do empreendimento. Nos termos do parágrafo $2^{\circ}$ do artigo 11 da MP 213, aderindo ao PROUNI, as instituições "filantrópicas" cassadas nos últimos seis anos poderão "solicitar ao ministro da Previdência o reexame de seus processos, com eventual restauração do certificado de entidade beneficente de assistência social e restabelecimento da isenção de contribuições sociais (...)”, jogando no lixo todos os autos milionários realizados pelos fiscais da Previdência, desde que provem ao MEC e não à Previdência (muito mais aparelhada para a fiscalização) que: 1) não remuneram os diretores; 2) reaplicam os lucros na própria entidade; 3) realizam algum tipo de benemerência. O problema, conforme assinala Josias de Souza (2004) na Folha de S. Paulo, é que essas exigências são "triviais" e não impedem a recorrência de fraudes. "Distribuição de lucros e desvios de finalidade não passeiam pelo mundo dos papéis oficiais" e o problema fundamental: a comprovação da aplicação de $20 \%$ de seu faturamento em benemerência "não foi incluída no rol de pré-requisitos para a reanálise de processos".

Caso todas as instituiçôes privadas venham a aderir ao PROUNI, haverá um subsídio superior a R \$ 2,0 bilhões/ano aos empresários, ${ }^{8}$ isso sem contar os cerca de R $\$ 1$ bilhão do FIES. É importante destacar que o número de vagas é muito inferior às metas originalmente estabelecidas. Inicialmente, o MEC previa 400 mil vagas; agora não passarão de $180 \mathrm{mil}$, meta a ser alcançada daqui a três anos, sendo metade composta de bolsas parciais (como os 50\% restantes serão custeados pelos alunos de baixa 
renda?!). A rigor, todos esses cursos poderiam ser na forma de "cursos seqüenciais" de curtíssima duração, a modalidade de educação minimalista "em" nível superior para os mais pobres. Da versão original à MP, o custo relativo de cada vaga foi multiplicado por 2,8!

Estudo da Associação Nacional dos Dirigentes das Instituições Federais de Ensino Superior, acolhido pelo relatório do GTI já mencionado, afirma que com apenas $\mathrm{R} \$ 1$ bilhão seria possível generalizar o ensino noturno das IFES, criando aproximadamente 400 mil novas vagas. Com o total de verbas públicas que está sendo previsto para as instituições privadas seria viável criar mais de um milhão de novas vagas. Os fatos desmentem o propósito social dessa política que faz avançar ainda mais a privatização do ensino superior, setor que totaliza $88 \%$ das instituições e $72 \%$ dos estudantes do ensino superior.

A pergunta sobre as reais motivações dessa medida é inevitável. Em um contexto de dramático estrangulamento orçamentário das instituições públicas, vítimas do draconiano superávit primário que fez secar as políticas públicas, por que tamanho desapreço pelas instituições públicas que tantas contribuiçóes têm dado ao povo brasileiro? Lula da Silva está convencido de que as privadas são socialmente mais democráticas. Contudo, essa crença, conforme o IBGE, é falsa. A renda dos estudantes das instituições privadas, comparando curso a curso, é superior à dos estudantes das públicas. Isso não quer dizer, em absoluto, que o ensino superior do país seja democrático. Longe disso, o Brasil é um dos países da América Latina com menor porcentual de jovens nesse nível de ensino. Se o motivo não é a justiça social alegada, como justificar essa medida?

Há dez anos, o Banco Mundial elaborou um documento afirmando que, no caso dos países latino-americanos, a única alternativa era instituir um sistema de educação superior assentado no setor privado, fortemente direcionado para o mercado, com cursos pragmáticos, em suma, em antípoda ao modelo europeu (Sguissardi, 2004). O PROUNI é esse modelo.

\section{Universidade, inovação tecnológica e fundações privadas}

A crise estrutural do capitalismo (Duménil \& Lévy, 1996) tem ensejado alternativas desenvolvidas pelo capital para reverter a curva descendente da taxa de lucros. A vertiginosa aceleração das inovações 
tecnológicas a que se refere Sevcencko (2001) é parte desse processo. Junto com essa aceleração, os tratados de propriedade intelectual tornaramse draconianos para os países capitalistas dependentes. Com efeito, o Acordo de Direitos de Propriedade Intelectual Relacionados ao Comércio (TRIPs), da OMC, ${ }^{9}$ repercutiu de modo intenso nas legislações nacionais que, via de regra, adotaram leis de patentes extremamente benéficas para os detentores do conhecimento estratégico.

Com as inovações, os espaços geográficos dispersos passaram a estar articulados com diversos ramos produtivos, possibilitando a difusão de empresas que, mantendo o seu centro geoestratégico nos países centrais, espalharam suas filiais para obter vantagens adicionais em termos de custo de mão-de-obra, tributos, energia e matérias-primas. Algumas regiōes viraram enclaves que servem de plataforma para a exportação em condiçôes extremamente vantajosas. $\mathrm{O}$ caso das maquilas, na fronteira norte do México, é ilustrativo dessa tendência. Atualmente esse país está entre os maiores exportadores de televisões, contudo as empresas são multinacionais e a tecnologia é exógena, as filiais apenas acoplam componentes e, quando muito, fazem ajustes tecnológicos para que a produção ocorra nas condiçôes de infra-estrutura existentes.

Um aparente paradoxo é estabelecido nos países da periferia: regióes até então desconectadas da produção industrial passam a produzir produtos de alta tecnologia, porém o aparato de pesquisa e de formação de quadros qualificados nesses países ou regiōes é submetido a calculado processo de desmonte. Os governos e os organismos internacionais engajados nesse processo de "modernização" empreendem mudanças que redefinem as instituições como "braços" dessas maquilas e plataformas de exportação. A proposta do chefe da Casa Civil, ministro José Dirceu, de que as instituições públicas terão de ser úteis ao setor produtivo aponta nessa direção: "Vamos mudar toda a relação da universidade com o empresariado, as empresas e os fundos de investimento". Citou, como bons exemplos, o ensino superior da China e da Coréia do Sul (Folha de S. Paulo, 5/12/2003), casos que não poderiam ser mais desastrosos para a universidade brasileira: ambos os países flexibilizaram a gratuidade e não asseguram liberdade de cátedra, sendo que, no que se refere à relação entre a oferta pública e privada, o modelo coreano é muito semelhante ao existente no Brasil; ademais, na Coréia grande parte da pesquisa é direcionada para três grandes conglomerados: Daewoo, Hyundai e LuckyGold Star. ${ }^{10}$ 
A tecnologia permite, em cada período histórico, uma articulação mundial diferente e engendra formas de lutas e resistências distintas. Por parte do capital, sua ideologia neoliberal sustenta a liberalização da economia dos países periféricos e semiperiféricos, exigindo proteção adicional por parte dos Estados (ver debate na seção dedicada ao PPP) e, ao mesmo tempo, combatendo toda tentativa de desenvolvimento autosustentado, compreendido como populista e arcaico.

A fragmentação das cadeias produtivas fragiliza intensamente os países fora do núcleo orgânico. Em caso de desacordo ou conflitos no âmbito nacional, não é difícil para o capital substituir um país (ou região) por outro em determinada etapa da produção.

Valendo-se da fetichização do capitalismo de hoje, a revolução científico-tecnológica é sustentada como um conceito válido também para a periferia e a semiperiferia. Reivindica-se alcance universal para o sedutor capitalismo intelectual. Destarte, as ideologias dominantes têm preconizado que os benefícios da nova economia serão para todos os que se prepararem para ela e, por isso, sustentam que a educação será a chave para o desenvolvimento, a prosperidade e o futuro da nação. Contudo, é preciso que as "velhas" universidades sejam convencidas de que não se trata de conhecimento acadêmico. O mercado requer conhecimento operacional e pragmático. É nesse contexto que a inovação tecnológica é inserida na agenda da educação superior da periferia do capitalismo.

A partir dos anos de 1990, novas noções, imagens, temas e referências com pretensão conceitual compõem o léxico da educação superior: produtividade, qualidade, competitividade, flexibilidade, gestão e eficiência. $\mathrm{O}$ metro para aferir a qualidade deixa de ser um determinado "ethos" acadêmico, tomando emprestado um outro sistema de medida: o mercado. Assim, a aferição é feita a partir de noções como produtividade, eficiência, excelência, flexibilidade e empreendedorismo.

Esse novo léxico denota transformações de grande alcance na universidade. Os currículos devem ser flexíveis e assegurar a aquisição de competências imediatamente comercializáveis no mercado. A pesquisa científica passa a ser equiparada à inovação e, por isso, o sistema de C\&T deve ganhar mais uma letra: CT\&I. Esse acréscimo tem implicações profundas. As universidades devem captar recursos no mercado, oferecendo, em contrapartida, serviços de inovação tecnológica. Mas aqui não é possível verificar uma sinergia positiva. Com Florestan Fernandes, é possível 
compreender o motivo pelo qual as empresas instaladas no país capitalista dependente não são, nem poderiam ser, intensivas em pesquisa e desenvolvimento (P\&D). A condição capitalista dependente tem como consequiência uma pequena demanda de cientistas e engenheiros, por isso as universidades não ocupam um lugar estratégico na agenda das coalizões dominantes. A adequação tecnológica, por ser episódica e de baixo perfil, acaba sendo indevidamente desviada para as universidades que, desse modo, têm suas funçôes ressignificadas, entrando no circuito do capital de forma imediata e pontual, impedindo tanto a autonomia em P\&D como a expansão e melhoria das universidades públicas.

Também no Brasil, todos os documentos governamentais que abordam o ensino superior e a política de C\&T proclamam apoio ao setor de CT\&I "sob pena de o país ficar excluído do novo padrão de desenvolvimento". No período desenvolvimentista, os governos chegaram a criar ministérios específicos para cuidar das políticas de desenvolvimento (inclusive industrial). Entretanto, na política real, notadamente a partir de Collor de Mello, está em curso um devastador processo de desindustrialização (UNCTAD, 2003) que afastou o setor produtivo da grande maioria dos produtos da nova geração (UNCTAD, 2004). O número de patentes relevantes continua muito abaixo do verificado nos países de perfil econômico semelhante. ${ }^{11}$ Tomando como indicador o número de cientistas e engenheiros (empresas, institutos de pesquisa e universidades), é possível observar a reduzida participação desse segmento no Brasil $(0,11 \%$ da força de trabalho), Coréía $(0,4 \%)$, EUA e Japão $(0,80 \%)$.

Ademais, é um equívoco supor que a Inovação é realizável na universidade. É a lógica do capital que transforma conhecimento plasmado no trabalho em mais-valia. E as empresas são os loci desse processo. Edwin Mansfield, da Universidade da Pensilvânia, constatou que apenas um em cada dez novos produtos ou processos teve a contribuição essencial e imediata na universidade, em definitivo: nove em cada dez inovações nascem na empresa. Mesmo nos EUA, o financiamento das universidades por meio de captação de recursos privados é reduzido: dos US\$ 27,5 bilhões contratados para pesquisa em todas as universidades estadunidenses em 1999 , apenas $7,5 \%$ foram provenientes de contratos com empresas. Os cerca de US\$ 2 bilhões captados nas empresas pelas universidades representam tão-somente $1,4 \%$ dos quase US\$ 180 bilhões investidos em P\&D nas empresas estadunidenses no referido ano (Cruz, 2003). 
A exemplo dos governos anteriores, também Lula da Silva manifestou-se a respeito da Inovação, concebendo-a mesmo como "a palavra-chave do vocabulário econômico de nosso tempo". O seu governo criou um Conselho Nacional e uma Agência Brasileira de Desenvolvimento Industrial e encaminhou ao Congresso Nacional um PL de Inovação Tecnológica (PL n. 3.476/2004).

\section{Projeto de Inovação Tecnológica}

Para converter toda vida universitária em assunto de homens de negócios, a ação do Estado é necessária. O Estado é chamado a compartilhar os custos crescentes do desenvolvimento tecnológico, a organizar e a dar "coerência" ao esforço científico e tecnológico de "sua" nação. Por fim, o Estado deve limitar e controlar, de acordo com os interesses da fração dominante do capital, a aplicação, cooperação e difusão do desenvolvimento de C\&T em seu território. No caso dos países de grande capacidade de produção em C\&T, o maior esforço tem sido no sentido de coibir a "pirataria" e a circulação de conhecimentos estratégicos (garantindo assim o monopólio tecnológico de sua nação). Países semiperiféricos subordinados atuam nesse mesmo sentido, reforçando as normas de propriedade intelectual. Concretamente, são as grandes corporaçōes que definem a pauta da produçáo estratégica, excetuando o caso da tecnologia militar, em que o Estado assume um papel crucial (Ornelas, 1995). No caso brasileiro, como destacado, os interesses da fração dominante do capital finanças, agronegócio e commodities - não estão requerendo a produção, no país, de novas tecnologias. O foco é posto na adequação e na certificação de processos e produtos.

O Projeto subordina as universidades ao campo empresarial, na medida em que estabelece que as empresas, de acordo com os seus interesses, definem o que será desenvolvido (ou comprado) em termos de serviços, adequações e produtos. Conforme o ministro do Desenvolvimento, é a empresa que induz a Inovação, cabendo à universidade o papel de servir ao setor privado. Inclusive, conforme Furlan, o apoio do governo poderá ser dado diretamente às empresas (Gobetti \& Nossa, 2004).

Se os países centrais estão atuando no sentido de endurecer os acordos de propriedade intelectual em benefício de suas empresas, seria de se esperar que os países com razoável grau de industrialização estivessem mobilizados para flexibilizar a propriedade intelectual. Con- 
tudo, apesar do fato de a lei de patentes aprovada na gestão Cardoso ser reconhecidamente uma das mais neocoloniais do mundo, o PL sequer aborda o problema.

O mesmo acanhamento não é verificado quando o PL trata da subordinação da universidade ao capital. O PL tem de ser compreendido no bojo das Parcerias Público-Privado (PPPs), que prevêem a aplicação de fundos federais em projetos de "interesse comum" para acelerar a incorporação de tecnologias pelas empresas. Os modelos chinês e coreano dos circuitos integrados de inovação e eficiência tornam as universidades uma repartição das grandes empresas. Isso seria efetivado, conforme o PL, a partir da criação de núcleos de inovação tecnológica nas instituições de ciência e tecnologia (ICT), que fariam a mediação da instituição com a empresa.

No caso de filiais (ou empresas que não possuem departamentos de P\&D), o PL estabelece que poderão subordinar as universidades à condição de meras prestadoras de serviços, atendendo a seus interesses específicos e imediatos. Essas ppps serão operacionalizadas por um órgão regulador, o Conselho Nacional de Desenvolvimento Industrial, cujo conselho deliberativo será constituído por oito representantes do Poder Executivo e por sete de entidades privadas. A agência reguladora - Agência Brasileira de Desenvolvimento Industrial -, organizada na forma de um "serviço social autônomo" (EM n. 0016/GM-MDIC), terá sua diretoria constituída pelo presidente da República, com mandato de quatro anos, podendo ser demissível ad nutum. Suas prerrogativas são: estabelecer os contratos de gestão (PPP); autonomia para contratar pessoal pela CLT e para estabelecer contratos de prestação com quaisquer pessoas físicas ou jurídicas.

O PL é ousado na ressignificação (melhor seria falar em desconfiguração) do trabalho docente. $\mathrm{O}$ processo de conversão do professor em um empreendedor é denominado eufemisticamente "modernização das relações de trabalho". A nova legislação, conforme o Ministério de C\&T, oferece uma espécie de gratificação para quem produzir conhecimentos que venham a ser usados por empresas: "Vamos dar ao pesquisador a oportunidade de ser também um empreendedor" (Campos, 2004). De fato, o art. $9^{\circ}$ do referido PL estabelece que o professor envolvido na prestação de serviço poderá receber contribuição pecuniária da instituição na forma de "adicional variável" ou, como estabelece o art. 10, "bolsa de estímulo à inovação". A conversão do professor em empreendedor (art. 14) 
está contemplada no PL. O inventor ou autor de projeto, processo ou serviço poderá participar em até um terço dos ganhos econômicos auferidos pela instituição. Até mesmo a transformação do professor em empresário é permitida. O docente pode se afastar por até seis anos da universidade para tentar uma carreira empresarial e até mesmo para constituir empresa. Durante o período de afastamento, é assegurado ao professor o vencimento do cargo efetivo, acrescido das vantagens pecuniárias permanentes estabelecidas em lei e, ainda, progressão funcional e benefícios da seguridade (arts. 15 e 16). A privatização do recurso público fica patente na medida em que valores que deveriam ser investidos nas universidades em pagamento de salários a docentes e funcionários e em pesquisas são utilizados para financiar docentes que tentam uma colocação no mercado como empreendedores, sem qualquer risco ou ônus para sua carreira profissional e sem qualquer custo para as empresas.

O professor empreendedor, embora possa fazer jus a alguma remuneração extra, terá de instituir a censura e a mordaça nas salas de aula e nos laboratórios. É vedado ao dirigente, ao criador ou a qualquer servidor, empregado ou prestador de serviços de ICT divulgar, noticiar ou publicar qualquer aspecto de criaçóes de cujo desenvolvimento tenha participado diretamente, ou tomado conhecimento por força de suas atividades, sem antes obter expressa autorização da ICT (art. 13). É importante ressaltar que o artigo citado não se refere apenas a sigilo sobre produção industrial, mas afeta inclusive questôes relativas à ética de pesquisa, notadamente em seres humanos e no meio ambiente, por exemplo proibindo a divulgação de efeitos nocivos de determinado procedimento ou substância. Seria de se esperar, ante o acúmulo de conhecimento produzido pelos Comitês de Ética em Pesquisa, que a legislação obrigasse a empresa a fazer tal divulgação, assim como o pesquisador e sua instituição de origem. O PL coloca a mordaça em todos, docentes, funcionários e estudantes, envolvidos ou não com o projeto em questão.

Por tudo o que foi dito sobre a inovação tecnológica, é coerente a edição do Decreto n. 5.205 de 14/9/2004, que regulamenta as fundações de apoio privadas nas instituições federais, eximindo-as de licitação, facultando-lhes contratar, por meio dessas fundações, "complementarmente pessoal não integrante dos quadros da instituição", bem como auferir bolsas de ensino, de pesquisa e de extensão inclusive para pessoal do quadro permanente. 
Cumpre ressaltar que todo conhecimento, tecnologia, processo ou produto derivado de investimento público - sob a forma de pessoal, instalações, equipamentos ou recursos - constitui patrimônio público, que deve ser acessível a todos e reverter em benefícios para toda a sociedade. A apropriação privada do conhecimento e seu uso para fins lucrativos não se inscrevem no campo ético, constituindo mais um elemento para sua desconstrução. Essa orientação colide não só com o preceito constitucional da autonomia didático-científica das universidades, como agride os princípios constitucionais de liberdade de produção, expressão e circulação de conhecimentos e saberes. O cerceamento da liberdade de produção de conhecimento é magnificado pelas radicais transformações da política de financiamento de C\&T. Com a inovação tecnológica, a universidade deixa de ser o espaço público de produção de conhecimento. Todo o exercício da crítica terá de ser um gesto de rebeldia intelectual.

\section{Considerações finais}

As parcerias público-privadas nas universidades podem parecer sedutoras em um contexto de baixos salários e de naturalização do empreendedorismo. Contudo, a exemplo das experiências das fundações privadas, os benefícios dessas atividades acabam privilegiando poucos e pequenos grupos, cujo foco de trabalho está dirigido para as atividades que as empresas consideram de seu interesse. Existem grupos que seguramente sairão fortemente favorecidos, como é possível constatar no Dossiê Fundações Privadas, organizado pela Seção Sindical dos Docentes da USP (ADUSP) (Biondi et al., 2001). Outros deslizarão numa zona de penumbra em que pequenos serviços, parte deles com relevância social, são remunerados. A maior parte vem lutando para perseverar na condição de docentes que se preocupam com o ensino, produzem conhecimento e defendem, não sem tensões e contradições, a universidade como um espaço público de produção e socialização do conhecimento.

Mas a institucionalização do ethos empreendedor vem provocando mudanças que se sucedem em um ritmo vertiginoso. A correlação de forças interna estará cada vez mais desequilibrada em favor dos capitalistas acadêmicos. Mesmo minoritários, estes setores que operam fora (e contra) dos frágeis espaços públicos gozarão de prestígio ante os que contratam serviços, a burocracia do aparato de fomento e os governos interessados em silenciar a universidade como lugar da crítica. 
Para fazer frente a esse processo de contra-reforma (Leher \& Sader, 2004) da universidade pública, os conselhos acadêmicos não poderão ser transigentes com essa dinâmica, sob pena de perderem autonomia de crítica e de verem os colegiados esvaziados. O movimento docente, por sua vez, estará sob a maior pressão de sua história. Como, potencialmente, o movimento fará a crítica mais radical a esse processo de privatização e desconstrução da universidade como espaço público, tanto os setores que se beneficiam da universidade como organização quanto os governos engajados no silenciamento da universidade estabelecerão alianças para derrotá-lo. O acompanhamento do movimento estudantil nos últimos anos sugere que este pode jogar um papel extremamente fecundo nesse processo. Ainda no plano político mais imediato, a direção majoritária da CUT tem concordância com esse projeto de conversão das instituições públicas em organizações sociais e, por isso, tomará para si a tarefa de derrotar os que combatem o projeto neoconservador interessado em impor um pensamento único na universidade.

$\mathrm{Na}$ concorrida Plenária Nacional do Fórum Nacional em Defesa da Escola Pública (FNDEP), realizada nos dias 10 e 11 de setembro de 2004, todas as entidades - ANDES-SN, Conselho Federal de Psicologia, CONTEE, CNTE, Executivas Nacionais de Cursos, FASUBRA e UNE - posicionaram-se contra o PROUNI. A demonstração do grau de isolamento da política do governo federal para a educação, ante as entidades que protagonizaram a luta em defesa da escola pública, não poderia ser mais eloqüente.

A expectativa dos 52 milhóes de brasileiros que votaram contra o neoliberalismo é de que a educação seja um direito fundamental e não uma mercadoria. Por isso, a reivindicação da universidade pública e gratuita como um direito de todos terá de ser buscada no espaço público. Outros setores, como a Via Campesina e os sindicatos que mantêm a sua autonomia, podem ser aliados estratégicos, pois, como sustentava Florestan Fernandes, não haverá uma reforma universitária de fato sem esses protagonistas. Como é a própria liberdade de produção do conhecimento que está em questão, entidades que se destacaram na luta pela liberdade de pensamento terão de ser convocadas, como a OAB, ABI e SBPC. Assegurar espaços públicos de produção de conhecimento é condição para avançar na luta pela autonomia cultural e pela superação da condição capitalista dependente.

Recebido e aprovado em setembro de 2004. 


\section{Notas}

1. Projeto de Lei n. 3.582/2004. Dispõe sobre o Projeto Universidade para Todos (ProunI). Após resistência de diversos setores sociais, como o Fórum Nacional em Defesa da Escola Pública, esse Projeto foi convertido em Medida Provisória (MP n. 213/2004).

2. Respectivamente: SINAES (Lei n. 10.861 de 14/4/2004); GTI (Grupo de Trabalho Interministerial. Brasília: 15 de dezembro de 2003. mimeo); prouni (PL n. 3.582/2004); Inovação Tecnológica (Brasil, PL n. 7.282/2002, e Decreto n. 5.205, de 14/9/2004. Regulamenta a Lei n. 8.958, de 20 de dezembro de 1994, que dispõe sobre as relações entre as instituiçóes federais de ensino superior e de pesquisa científica e tecnológica e as fundaçôes de apoio).

3. Mudança de cálculo do déficit público ainda demanda algum tempo. Teresa Ter-Minassian disse que o projeto das Ppps deveria ser aprovado pelo Congresso porque "é um instrumento importante para superar os gargalos" na área de infra-estrutura (Folha de S. Paulo, 2004).

4. O setor público (União, estados, municípios e estatais) registrou um superávit de R\$ 63,7 bilhōes nos primeiros oito meses do ano. A economia de recursos feita para o pagamento de juros é equivalente a $5,8 \%$ do PIB. Esse é o maior superávit para o período desde o início da série, em 1991. O montante acumulado já está R\$ 6,8 bilhôes acima da meta para este mês, que é de R\$ 56,9 bilhôes. Até o final do ano, a meta é economizar R\$ 71,5 bilhões.

5. Dados do BC e STN, Valor Econômico, p. C-1, 19/2/2004.

6. O Grupo de Trabalho Interministerial foi coordenado pela Casa Civil e pela Secretaria-Geral da Presidência com a participação do MEC e dos órgãos de fomento à c\&T.

7. Este autor destaca que a diluição da fronteira entre o público e o privado está presente no plano para o ensino superior elaborado pela Associação Nacional de Universidades e Instituições de Educação Superior (ANUIES), e que vem sendo aplicado pelo Governo Fox.

8. O cálculo realizado a partir de metodologia do Estudo Setorial, da Gazeta Mercantil, considera um índice de inadimplência da ordem de $30 \%$ para as filantrópicas, comunitárias e confessionais e de $25 \%$ para as empresariais.

9. Acordo de Direitos de Propriedade Intelectual Relacionados ao Comércio (TRIPs, em sua sigla em inglês), criado em Marrakesh, em 1994, que vigora desde 1995, já no escopo da OMC. É o principal tratado sobre os direitos de propriedade intelectual, abarcando patentes, direitos de autoria e marcas. Os TRIPs obrigam todos os membros da OMC a outorgar aos proprietários das patentes um monopólio temporal sobre as suas "invençōes" e, conforme o seu artigo $27.3 \mathrm{~b}$, até mesmo sobre seres vivos.

10. Com as recentes reformas, a China passou a cobrar taxas escolares, extinguindo a gratuidade, e o cerceamento à liberdade de pensamento é rigoroso. A Coréia segue o modelo estadunidense: $70 \%$ das instituiçôes são privadas (correspondendo a cerca de $80 \%$ do total de alunos). Nesse país, os docentes não dispõem de estabilidade em seus cargos e é comum o afastamento por delitos de opinião.

11. De fato, comparando com a Coréia, a situação brasileira é muito débil. Em 1990, o Brasil teve 41 patentes registradas nos EUA; a Coréia, 225. Em 2001, o Brasil registrou 110 e a Coréia 3.538; em 1990 o país registrou 5,5 vezes menos patentes nos EUA do que a Coréia, e em 2001 o Tigre Asiático obteve 32 vezes mais registros que os brasileiros. 


\section{Referências bibliográficas}

ABOITES, H. El dilema: la universidad mexicana al comienzo de siglo. México, DF: UCLAT-APN/UAM, 2001.

ALTBACH, P. Educación superior comparada. Buenos Aires: Universidad de Palermo, 2001. p. 113-116, 352-354.

ANDERSON, P. Idéias e ação política na mudança histórica. Margem esquerda, São Paulo, n. 1, mai. 2003.

BIONDI, A. et al. Fundações demais, transparência de menos. Revista ADUSP, São Paulo, n. 22, mar. 2001.

BRASIL. CASA CIVIL. EM n. 355/2003/MP/MF, Brasília, DF, 10 de novembro de 2003.

BRASIL. CASA CIVIL. Exposição de Motivos n. 355/2003, 10 de novembro de 2003; PL n. 2.546/2003. Dispōem sobre a Parceria Público-Privado.

BRASIL. MINISTERIO DA EDUCAÇÃO. Reforma da educação superior: reafirmando princípios e consolidando diretrizes da reforma da educação superior. Documento II. Brasília, DF: MEC, 2004.

BRASIL. MINISTERIO DA EDUCAÇÃO. GRUPO DE TRABALHO INTERMINISTERIAL. Bases para o enfrentamento da crise emergencial das universidades federais e roteiro para a reforma universitária brasileira. Brasília, DF: MEC, 2003.

BRASIL. MINISTERIO DA FAZENDA. Gasto Social do Governo Central: 2001 e 2002. Brasília, DF, 2003. Disponível em: <http:// www.fazenda.gov.br>.

BRASIL. Projeto de Lei n. 3.582 de 2004. Dispõe sobre a instituiçãao do Programa Universidade para Todos - PROUNI, regula a atuação de entidades beneficentes de assistência social no ensino superior e dá outras providencias.

CALIARI, T. Parcerias público-privadas: o diabo mora nos detalhes. Reportagem da Oficina de Informaçoes, v.5, n.55, abr. 2004.

CHAUI, M. A nervura do real. São Paulo: Cia das Letras, 1999. 
CRUZ, C.H.B. A universidade, a empresa e a pesquisa. In: SEMINARIO Brasil em Desenvolvimento, out. 2003, Rio de Janeiro. Rio de Janeiro: Instituto de Economia da UfrJ, 2003.

DIRCEU, J. Folha de S. Paulo, São Paulo, 5 dez. 2003.

DUMÉNIL, G.; LÉVY, D. La dynamique du capital: un siècle d'économie américaine. Paris: PUF, 1996.

DUPAS, G. Tensóes contemporâneas entre o público e o privado. São Paulo: Paz \& Terra, 2003.

GOBETTI, S.; NOSSA, L. O Estado de S. Paulo, São Paulo, 29 abr. 2004. HASHIZUME, M. MEC propõe “PPP” para criar vagas públicas em particulares. $O$ Estado de S. Paulo, São Paulo, 16 fev. 2004. Disponível em: <http://www.estadao.com.br>. Acesso em 17 fev. 2004.

JURUÁ, C.V. PPP: os contratos de parceria publico-privada; conferência apresentada ao Instituto de Economia da UfRJ. Disponível em: $<$ http://www.outrobrasil.net>. Acesso em 10 set. 2004.

LEHER, R.; SADER, E. Público, estatal e privado na reforma universitária. 2004. (Texto elaborado para o INEP. mimeo)

NUNES, S.P. Parcerias público-privadas. Brasilia, DF: InEsc, 2004. (Nota Técnica $n$. 87).

ORNELAS, R. La inversión el desarrollo tecnológico como elemento del liderazgo económico internacional: algunas tendencias de la interacción estados-empresas. In: CECEÑA, A.E. (Comp.). La internacionalización del capital e sus fronteras tecnológicas. Coyoacán, Mx: El Caballito, 1995.

PIVETTA, M. O salto quântico da ciência brasileira. Revista Pesquisa FAPESP, São Paulo, n. 100, jun. 2004.

POLANYI, K. A grande transformação: as origens de nossa época. Rio de Janeiro: Campus, 2000.

RIBEIRO, A.P. Setor público acumula superávit primário de 5,8\% do PIB até agosto. Folha Online. Disponível em: <http://www1.folha.uol.com.br/ folha/dinheiro/ult91u89286,shtm1>. Acesso em 26 set. 2004.

ROSENBURG, C. Nota alta. Exame, ed.763, v. 36, n. 7, abr. 2002. 
SEVCENCKO, N. A corrida para o século XXI: no loop da montanharussa. São Paulo: Cia das Letras, 2001.

SGUISSARDI, V. Rumo à universidade mundial: e a universidade será feita a sua imagem e semelhança. 2004. (Texto elaborado para o INEP).

SLAUGHTER, S.; LESLIE, L.L. Academic capitalism: politics, policies and the entrepreneurial university. Baltimore: Johns Hopkins University, 1999.

SOUZA, J. Medida provisória do PROUNI cria o "promamata". Folha de S. Paulo, São Paulo, 26 set. 2004. Caderno 1.

THERNBORN, G. La ideologia del poder y el poder de la ideologia. México, DF: Siglo XXI, 1987.

UNCTAD. World Investment Report 2003.

UNCTAD. World Investment Report 2004. 